\title{
REVIEWS
}

Bartosz Rabiega $^{1, \text { A-D }}$, Wojciech Eliasz ${ }^{1, \text { A-D }}$, Krzysztof Pawlaczyk ${ }^{2, \text { E, F }}$

\section{Oral Health in Chronic Kidney Disease Patients: A Literature Review}

\section{Stan jamy ustnej u pacjentów z przewlekłą niewydolnością nerek - przegląd piśmiennictwa}

1 Department of Conservative Dentistry and Periodontology, Poznan University of Medical Sciences, Poznań, Poland

2 Department of Nephrology, Transplantology and Internal Diseases, Poznan University of Medical Sciences, Poznań, Poland

A - research concept and design; $\mathbf{B}$ - collection and/or assembly of data; $\mathbf{C}$ - data analysis and interpretation;

$\mathbf{D}$ - writing the article; $\mathbf{E}$ - critical revision of the article; $\mathbf{F}$ - final approval of article

\begin{abstract}
Chronic kidney disease (CKD), which is becoming an important public health issue worldwide, is a broad term used to describe progressive structural and functional kidney disorders that may be accompanied by a decrease in the glomerular filtration rate (GFR), and that have lasted for at least 3 months. The reason for concern about patients with CKD stems from the impairment in everyday functioning caused by this disease, as well as from the complexity of treatment needed in these cases. Contemporary literature indicates that there are several oral health-related symptoms that may be associated with CKD and, therefore, it may be the dental practitioner who refers the patient for comprehensive specialist care in the earlier stages of the disease. The aim of the article is to present a concise literature review concerning the symptoms in the oral cavity that may be associated with CKD. The authors discussed the occurrence of characteristic features in dental hard tissues, the periodontium, and oral mucosa. It can be established on the basis of the literature that some characteristic features in the dental clinical picture may be observed in these patients, and that dental clinicians should be made aware of this fact (Dent. Med. Probl. 2016, 53, 3, 419-423).
\end{abstract}

Key words: chronic kidney disease, oral mucosa, chronic periodontitis, dental caries, oral health.

Słowa kluczowe: przewlekła niewydolność nerek, błona śluzowa jamy ustnej, przewlekłe zapalenie przyzębia, próchnica zębów, zdrowie jamy ustnej.

Chronic kidney disease (CKD) is a broad term used to describe progressive structural and functional kidney disorders that may be accompanied by a decrease in the glomerular filtration rate (GFR), and that have lasted for at least 3 months [1]. The diagnosis of CKD is also made if GFR values are below $60 \mathrm{~mL} / \mathrm{min} / 1.73 \mathrm{~m}^{2}$ for a minimum of 3 months, independently of the presence of kidney damage markers $[2,3]$. There are several symptoms that can indicate CKD in patients, e.g. abnormalities visible in diagnostic imaging procedures, in blood and urine tests (e.g. proteinuria, abnormal urine sediment) or blood morphology. GFR is, however, the most important factor when it comes to the physiopathology of chronic kidney disease. Nowadays, $\mathrm{CKD}$ is classified into five stages, according to the value of this index: stage 1 (GFR $>90 \mathrm{~mL} /$ $\left./ \mathrm{min} / 1.73 \mathrm{~m}^{2}\right)$, stage $2\left(60-89 \mathrm{~mL} / \mathrm{min} / 1.73 \mathrm{~m}^{2}\right)$, stage $3\left(30-59 \mathrm{~mL} / \mathrm{min} / 1.73 \mathrm{~m}^{2}\right)$, stage $4(15-29$ $\left.\mathrm{mL} / \mathrm{min} / 1.73 \mathrm{~m}^{2}\right)$ and stage $5(\mathrm{GFR}<15 \mathrm{~mL} /$ $\left./ \mathrm{min} / 1.73 \mathrm{~m}^{2}\right)$. Stage 3 can be further divided into $3 \mathrm{~A}\left(45-59 \mathrm{~mL} / \mathrm{min} / 1.73 \mathrm{~m}^{2}\right)$ and $3 \mathrm{~B}(30-44 \mathrm{~mL} /$ $\left./ \mathrm{min} / 1.73 \mathrm{~m}^{2}\right)$. Stage 5 , the most advanced and dangerous one, is also described as "end-stage renal failure" (ESRF), and constitutes an indica- 
tion for renal replacement therapy (haemodialysis or peritoneal dialysis), or even for the transplant of the affected organ [3].

Epidemiological data concerning the incidence of CKD indicates values that reach up to 400 cases per million annually in the United States, Taiwan and Mexico [1]. According to statistics, the percentage of patients suffering from CKD in Poland is approximately $11 \%$. However, the interpretation of epidemiological data may pose some difficulties, as the early symptoms of CKD may not be possible to identify by the patients or be noticeable in laboratory test outcomes. At the same time, elderly people experience a physiological decline in renal functioning, which may lead to the diagnosis of CKD being made too promptly. The estimated number in CKD patients is expected to rise at the rate of 5-8\% annually, which may be related to the overall age of the population being on the increase and to a significant increase in the number of type 2 diabetes patients $[4,5]$.

Systemic diseases such as diabetes, hypertension, obesity and cardiovascular disorders, constitute the commonly accepted aetiological factors of chronic kidney disease. Disorders that damage the interstitial tissue of the organ with the use of non-inflammatory pathway, mostly the diabetic kidney disease (previously known as diabetic nephropathy) and hypertension nephropathy prevail in this group. It should, however, be taken into account, that the diagnosis of chronic kidney disease is often made when structural or functional disorders are observed over the course of glomerular kidney disorders, autoimmune disorders in which the secondary changes in the kidney are observed (e.g. systemic lupus erythematous), vascular inflammation, bacterial and viral infection, tubulointerstitial renal disorders (e.g. toxic influence of drugs), some genetic disorders (polycystic kidney, Alport syndrome) [6].

The aim of the article is to provide the reader with information from literature, concerning the oral symptoms observed in patients with chronic kidney disease.

\section{Chronic Kidney Disease and Disorders of Dental Hard Tissues}

Contemporary research studies seem to indicate that there are two aspects concerning the state of dental hard tissues, in which differences between patients suffering from CKD and healthy people are observed, i.e. decreased susceptibility to caries and more frequent occurrence of hypoplastic enamel lesions [7-9].
It was observed as early as in the 1980s that the patients suffering from CKD in its more severe stages, particularly the failure stage, in which disturbances in urea are observed, exhibit lower values of caries indices [7,8]. More recent studies seem to confirm these observations $[9,10]$. In order for a carious cavity to develop, the occurrence of several factors is necessary: low salivary $\mathrm{pH}$, the presence of cariogenic bacteria and the influence of these factors during the appropriate time span. The salivary $\mathrm{pH}$ values in $\mathrm{CKD}$ was shown to be statistically significantly higher due to impairment in kidney functioning, which in turn leads to impairment in the removal of urea from blood. That is why the levels of urea are also higher in saliva. The hydrolysis of its compounds leads to the development creation of ammonia compounds, which are alkaline in nature. Moreover, Al-Nowaiser et al. [9] observed that observed cases of Streptococcus mutans bacteria are statistically significantly less frequent in children subjected to haemodialysis, due to end-stage renal disease. According to some researchers, the influence of urea as an antimicrobial agent may be responsible for this observation. What seems interesting, patients with CKD usually are on a low-protein diet, in which the majority of food consists of carbohydrate-rich foods, which usually leads to an increase in caries risk [11].

Developmental disorders of enamel are, on the other hand, more frequently observed in these patients. The most frequently observed types are enamel hypoplasia or fluorosis, and lesions of this type are observed in patients, in whom kidney pathology developed earlier in the developmental period [12-14]. These lesions are mostly caused by impairment in the calcium-phosphorus metabolism, and are statistically significantly more frequent in pediatric patients, in whom kidney disorders have already developed during the stage of dental hard tissues mineralization. That is why the clinicians should bear in mind that the location of the lesions may indicate the exact point in time in which the disorders developed. Warady et al. [14] also observed the lesions characteristic of fluorosis in those patients, particularly in permanent dentition, and linked it with increased levels of fluoride in blood.

\section{Chronic Kidney Disease and Periodontal Status}

Chronic periodontitis constitutes one of the factors that contribute to the development of chronic kidney disease, and the relationship between those two entities is bi-directional [15-19]. 
The epidemiological studies, whose aim was to compare CKD patients with normal controls, showed interesting differences when it comes to periodontal status. In the group of CKD patients, higher plaque and calculus accumulation, bigger amounts of such deposits, and severe course of periodontitis were observed [20]. Moreover, one should take into account hyperplastic gingival lesions that can develop due to immunosuppressive therapy after transplantation or because of the influence of calcium channel blockers used for treating nephrogenic hypertension in these patients [21].

Increased calculus deposition is linked in literature mainly with the same factor which is attributed to decreased susceptibility to caries, i.e. increased salivary $\mathrm{pH}$ values caused by the presence of urea and its compounds in the saliva of these patients [22]. This leads to quicker and more pronounced mineralization of dental plaque, whose indices in these patients are also higher. These observations were confirmed in several research studies conducted at various research centers. However, Akar et al. [23] indicated that multi-center trials should be conducted in order to develop effective strategies for dealing with oral diseases and promoting oral health. Such trials should include a comparison of patients from different countries.

Increased amounts of dental plaque and, to a smaller extent, calculus, theoretically should suggest that the prevalence of gingivitis and chronic periodontitis should be higher in CKD patients than in health population. It should also be taken into account that increased levels of uremic toxemia leads to disorders in the functioning of the immune system, which may contribute to the development of chronic inflammatory process within the periodontal tissues [24]. The outcomes of measurements that evaluate bleeding, such as Gingival Index, Sulcus Bleeding Index, or Papillary Bleeding Index may not be credible in patients with CKD, as during hemodialysis they receive anticoagulant medications, mostly heparins [25]. Even though the outcomes of research studies indicate that chronic periodontitis is observed more frequently and is characterized by a severe course in CKD patients, Craig [20] indicates that, while conducting any studies in these topics, one should take the coexistence of type 2 diabetes, smoking, duration time of dialysis, as well as demographic factors into account.

Another important periodontal symptom that should be taken into account is gingival hyperplasia. Such lesions are observed in patients after a kidney transplant treated with cyclosporine A [26]. Decreased prevalence of this complication was observed after cyclosporine was replaced with tacro- limus [21]. Another cause for the development of gingival hyperplasia is the use of calcium channel blockers, such as e.g. nifedypin. Along with increased calculus deposition, the patients encounter greater difficulties with maintaining oral hygiene, which in turn leads to deterioration in oral health [21].

That is why particular attention should be paid to the issues of oral hygiene in CKD patients. The role of the dentist is not limited to treating already existing disorders, but should also include a multifactorial education of the patient in the domain of professional and home oral hygiene maintenance methods.

\section{Oral Mucosal Lesions}

The next group of symptoms that can be observed in the course of CKD in the oral cavity are the lesions that develop within the oral mucosa. A concise summary of such lesions types was published by Proctor et al. [27] and stated that in most cases these lesions are: white and red spots, eruptions, lichen-like lesions, hairy leukoplakia, uremic stomatitis, maculae, polyps, geographical tongue, black hairy tongue, papillomas and inflammatory granuloma. Also, the patients report complaints of dry mouth, halitosis and gustatory disorders [28, 29]. The development of most inflammatory lesions, such as stomatitis or ulcerations, is attributed to the irritating influence of urea found in saliva. These patients are also more prone to the development of lesions such as petechiae, which is associated with the use of anticoagulants, as well as the effect of uraemia on platelet aggregation [30]. The lesions of hairy leukoplakia-type or lesions that manifest themselves in a way similar to Kaposi's sarcoma, can most probably result from the negative influence of urea on the functioning of the immune system, and in the patients who received the transplant - with the immunosuppression therapy used. It should also be noted that lesions that mimic hairy leukoplakia may develop in CKD patients in the absence of EBV infection and may be caused by the irritating influence of urea.

When discussing oral mucosal lesions, it should be particularly noted that they influence negatively not only the state of the oral cavity, but also on the patient's systemic health [21]. Improper oral hygiene and coexisting chronic periodontitis may lead to tooth loss, and oral mucosal lesions may make it more difficult, or even impossible, to restore dentition with the use of various prosthodontic devices. These factors, along with psychological issues, lead to a limitation in food intake and malnutrition, which, in turn leads to the de- 
velopment of the Protein Energy Wasting (PEW) syndrome (the state of decreased protein and nutrient reserve). In the most severe form it may result in the patient being cachexic. This seems extremely important, as PEW is an important prognostic factor used to predict the morbidity in CKD patients [31].

\section{Summary}

Scientific literature suggests that patients suffering from chronic kidney disease may exhibit characteristic symptoms in the oral cavity. One of the most commonly discussed is their decreased susceptibility to caries, more frequent occurrence of enamel hypoplasia, higher values of calculus and plaque indices, gingival hyperplastic lesions and oral mucosal lesions. In most cases, the development of these lesions is attributed to the characteristic composition of these patients' saliva, such as its higher $\mathrm{pH}$, the presence of urea and its compounds. It should also be noted that the relationship between chronic inflammatory process in the kidneys and in the oral cavity is bidirectional. Therefore, also untreated chronic periodontitis, improper oral hygiene and the lack of dental control lead to those patients exhibiting worse functioning in everyday life, e.g. due to impairment in eating, which in turn leads to a significant decrease in the patient's quality of life, systemic health and the general prognosis.

\section{References}

[1] Levey A.S., Coresh J.: Chronic kidney disease. Lancet, 2012, 379 (9811), 165-180.

[2] Levin A., Hemmelgarn B., Culleton B., Tobe S., McFarlane P., Ruzicka M., Burns K., Manns B., White C., Madore F., Moist L., Klarenbach S., Barrett B., Foley R., Jindal K., Senior P., Pannu N., Shurraw S., Akbari A., Cohn A., Reslerova M., Deved V., Mendelssohn D., Nesrallah G., Kappel J., Tonelli M.: Guidelines for the management of chronic kidney disease. CMAJ, 2008, 179, 1154-1162.

[3] Tomino Y.: Pathogenesis and treatment of chronic kidney disease: A review of our recent basic and clinical data. Kidney Blood Press. Res. 2014, 39, 450-489.

[4] Ruggenenti P., Schieppati A., Remuzzi G.: Progression, remission, regression of chronic renal diseases. Lancet, 2001, 357 (9268): 1601-1608.

[5] El Nahas A.M., Bello A.K.: Chronic kidney disease: the global challenge. Lancet, 2005, 365 (9456), 331-340.

[6] Warady B.A., Сhadha V.: Chronic kidney disease in children: The global perspective. Pediatr. Nephrol. 2007, 22, 1999-2009.

[7] Laisi T.J., Raji Y.R., Salako B.L.: Salivary creatinine and urea analysis in patients with chronic kidney disease: A case control study. BMC Nephrol. 2016, 17: 10. DOI: 10.1186/s12882-016-0222-x.

[8] Tadakamadla J., Kumar S., Mamatha G.P.: Comparative evaluation of oral health status of chronic kidney disease (CKD) patients in various stages and healthy controls. Spec. Care Dentist. 2014, 34, 122-126.

[9] Al Nowaiser A., Roberts G.J., Trompeter R.S., Wilson M., Lucas V.S.: Oral health in children with chronic renal failure. Pediatr. Nephrol. 2003, 18, 39-45.

[10] Andrade M.R.T.C., Antunes L.A.A., De Araújo Soares R.M., Leão A.T.T., Maia L.C., Primo L.G.: Lower dental caries prevalence associated to chronic kidney disease: A systematic review. Pediatr. Nephrol. 2014, 29, 771-778.

[11] Beto J.A., Schury K.A., Bansal V.K.: Strategies to promote adherence to nutritional advice in patients with chronic kidney disease: A narrative review and commentary. Int. J. Nephrol. Renovasc. Dis. 2016, 9, 21-33.

[12] Davidovich E., Davidovits M., Eielman E., Schwartz Z., Bimstein E.: Oral findings and periodontal status in children, adolescents and young adults suffering from renal failure. J. Clin. Periodontol. 2005, 32, 1076-1082.

[13] Lucas V.S., Roberts G.J.: Oro-dental health in children with chronic renal failure and after renal transplantation: A clinical review. Pediatr. Nephrol. 2005, 20, 1388-1394.

[14] Warady B.A., Koch M., O’Neal D.W., Higginbotham M., Harris D.J., Hellerstein S.: Plasma fluoride concentration in infants receiving long-term peritoneal dialysis. J. Pediatr. 1989, 115, 436-439.

[15] Pizzo G., Guiglia R., Russo L.L., Campisi G.: Dentistry and internal medicine: from the focal infection theory to the periodontal medicine concept. Eur. J. Intern. Med. 2010, 21, 496-502.

[16] Wahid A., Chaudry S., Ehsan A., Butt S., Kahn A.A.: Bidirectional relationship between chronic kidney disease \& periodontal disease. Pak. J. Med. Sci. 2013, 29, 1, 211-215.

[17] Duran I., Erdemir E.O.: Periodontal treatment needs of patients with renal disease receiving haemodialysis. Int. Dent. J. 2004, 54, 274-278.

[18] Chambrone L., Foz A.M., Gugliemetti M.R., Pannuti C.M., Artese H.P., Feres M., Romito G.A.: Periodontitis and chronic kidney disease: A systematic review of the association of diseases and the effect of periodontal treatment on estimated glomerular filtration rate. J. Clin. Periodontol. 2013, 40, 443-456.

[19] IoAnnidou E., Swede H.: Disparities in periodontitis prevalence among chronic kidney disease patients. J. Dent. Res. 2011, 90, 730-734.

[20] Craig R.G.: Interactions between chronic renal disease and periodontal disease. Oral Dis. 2008, 14, 1-7.

[21] Radwan-Oczko M., Boratyńska M., Zį̨tek M.: Clinical evaluation of marginal parodontium condition in patients after kidney graft treated with calcineurine inhibitors and calcium channel blockers. Bull Group Int. Rech. Sci. Stomatol. Odontol. 2004, 46, 46-51. 
[22] Bots C.P., Poorterman J.H., Brand H.S., Kalsbeek H., Amerongen B.M., Veerman E.C.I., Nieuw AmeronGEN A.V.: The oral health status of dentate patients with chronic renal failure undergoing dialysis therapy. Oral Dis. 2006, 12, 179-180.

[23] Akar H., Akar G.C., Carrero J.J., Stenvinkel P., Lindholm B.: Systemic consequences of poor oral health in chronic kidney disease patients. Clin. J. Am. Soc. Nephrol. 2011, 6, 218-226.

[24] Cohen G., Haag-Weber M., Hörl W.H.: Immune dysfunction in uremia. Kidney Int. Suppl. 1997, 62, s79-s82.

[25] Borawski J., Wilczyńska-Borawska M., Stokowska W., Myśliwiec M.: The periodontal status of pre-dialysis chronic kidney disease and maintenance dialysis patients. Nephrol. Dial. Transplant. 2007, 22, 457-464.

[26] Somacarrera M.L., Hernández G., Acero J., Moskow B.S.: Factors related to the incidence and severity of cyclosporin-induced gingival overgrowth in transplant patients. A longitudinal study. J. Periodontol. 1994, 65, 671-675.

[27] Proctor R., Kumar N., Stein A., Moles D., Porter S.: Oral and dental aspects of chronic renal failure. J. Dent. Res. 2005, 84, 199-208.

[28] Kнo H.S., Lee S.W., Chung S.C., KIm Y.K.: Oral manifestations and salivary flow rate, pH, and buffer capacity in patients with end-stage renal disease undergoing hemodialysis. Oral Surg. Oral Med. Oral Pathol. Oral Radiol. Endod. 1999, 88, 316-319.

[29] de la Rosa García E., Mondragón Padilla A., Aranda Romo S., Bustamante Ramírez M.A.: Oral mucosa symptoms, signs and lesions, in end stage renal disease and non-end stage renal disease diabetic patients. Med. Oral Patol. Oral Cir. Bucal. 2006, 11, E467-E473.

[30] Swapna L.A., Reddy R.S., Ramesh T., Reddy R.L., Vijayalaxmi N., Karmakar P., Pradeep K.: Oral health status in haemodialysis patients. J. Clin. Diagn. Res. 2013, 7, 2047-2050.

[31] Jadeja Y.P., Kher V.: Protein energy wasting in chronic kidney disease: An update with focus on nutritional interventions to improve outcomes. Ind. J. Endocrinol. Metab. 2012, 16, 246-251.

\section{Address for correspondence:}

Wojciech Eliasz

Department of Conservative Dentistry and Periodontology

Poznan University of Medical Sciences

Bukowska 70

60-812 Poznań

Poland

E-mail: wojciecheliasz@live.com

Conflict of interest: None declared

Received: 12.04 .2016

Revised: 7.05.2016

Accepted: 20.05.2016 